\title{
LA DOCTRINA DE LAS MINORÍAS EN ORTEGA Y SUS CRÍTICOS
}

José LASAGa MEdiNA

Este trabajo es continuación y, en cierto modo, consecuencia de un artículo titulado "Cultura y política: el gozne del liberalismo»", centrado en el examen comparativo de un ensayo de filosofía Meditaciones del Quijote (MQ) y un programa de reforma social basado en una conferencia, Vieja y nueva política (VNP). Traté ahi de exponer, a través de sus préstamos, comunicaciones y convergencias la mirada - la perspectiva- desde la que uno y otro hallan su unidad profunda: el «principio liberal». Quedaron varias cuestiones sin tocar. Entre otras, la de analizar la evolución de esta concepción liberal del pensamiento político orteguiano - si es que hay tal, así, substantivado y separado de su filosofar tout court-, surgida y pensada desde una determinada visión de la articulación vida-cultura. Quede para otra ocasión. En lo que sigue, pretendo comentar algunos aspectos, especialmente polémicos, que acompañan, como el escándalo a la dama galante, esta adscripción al liberalismo que Ortega mantuvo siempre (aunque no dejara de matizarla), cuando opinó y actuó en la cosa pública. Una de ellas fue apuntada: la tensión entre el principio liberal y el principio democrático, tensión que, según se argumentó, no tiene por qué interpretarse en términos excluyentes, si cada uno de los principios se mantiene en su punto de salud y equilibrio: ni el liberalismo

1 Aparecerá publicado en Claves de la razón práctica, $\mathrm{n}^{2}$ de julio-agosto de 1996. Las referencias a Ortega se dan por su edición de Obras completas, Madrid, Alianza-Revista de Óccidente, doce vols. 1983. El romano indica el volumen y la cifra árabe la página.

Éndoxa: Series Filosóficas, $n^{2} 7,1996$, UNED, Madrid:

losé Lasaga: La doctrina de las minorías en Ortega y sus críticos.

pp. 2.31- 255. 
degenerar en individualismo anticomunitario, ni la democracia en igualitarismo injusto para con las inevitables y legítimas diferencias.

Esto es claro en Vieja y nueva politica (VNP), cuya conclusión es «liberalismo y nacionalización», uno junto a la otra, pues Ortega cree que el lugar (común) a abandonar es «la forma individualista del liberalismo" ( $I, 303$ ). Y es justamente esta insuficiencia del liberalismo individualista lo que corrige el segundo elemento de la conclusión, la nacionalización, término que designa la necesidad de un estado fuerte, interventor en la vida social, cuyas instituciones, basadas en la eficacia, han de contribuir a la organización de la sociedad española. El Estado es un magnífico instrumento para coadyuvar a la salvación de la crisis nacional y es muy difícil encontrar en Ortega juicios "neoliberales» —en el sentido periodístico actual-, si bien defiende siempre que hay que estar en claro respecto de lo que ni se puede pedir ni se puede esperar del Estado.

Una segunda cuestión, más espinosa, es la de las minorías. $\mathrm{Si}$ hay en Ortega una teoría de las minorías, lo primero que conviene aclarar es que, a diferencia de la de Lenin, no pertenece a la esfera de lo político, ni, en consecuencia, tiene que ver con la conquista de los mecanismos estatales del poder. Es más, si se extrema el rigor, tampoco es propiamente una teoría social, sino histórica ${ }^{2}$. Ya se ha dicho que no es posible exponerla aquí. Tampoco hace falta, teniendo en cuenta que hay estudios solventes ${ }^{3}$. Me interesa

2 De sus críticos marxistas, Tuñón de Lara es el único en señalar este matiz. Medio siglo de cultura española (1885-1936), Madrid, Tecnos, 1987, p. 225.

${ }^{3}$ Son buenas introducciones el libro de Ignacio Sánchez Cámara La teoría de la minoría selecta en el pensamiento de Ortega y Gasset (Madrid, Tecnos, 1986) y el artículo de Domingo Blanco "El aristocratismo de Ortega", en Sistema, Madrid, $\mathrm{n}^{2}$ 76, enero 1987, pp. 73-101. También los capítulos correspondientes de El derecho en Ortega de José Hierro Sánchez-Pescador. Madrid, Revista de Occidente, 1965. (Las obras que los discípulos directos de Ortega como J. Marías, A. Rodríguez Huéscar, P. Garagorri, etc., han dedicado al análisis del pensamiento político de su maestro contienen siempre exposiciones 
únicamente destacar la relación entre el liberalismo orteguiano y su análisis del papel histórico de las minorías, atendiendo, de paso, a las críticas de que ha sido objeto. Pudiera parecer fuera de lugar entrar en polémica con textos que tienen algunos años. Ni siquiera puedo estar seguro de que sus autores sostengan aún aquellas opiniones. Sin embargo, creo que son escritos activos, es decir, con vigencia: influyen en el estado de opinión que se tiene sobre la vertiente política de la obra de Ortega.

En efecto, algunas de las críticas detectan una ruptura o cambio sustancial en la evolución del pensamiento político orteguiano para hacer compatible al Ortega crítico radical de la Restauración y defensor de la modernidad con el "conservador" que despliega a partir de España invertebrada una teoría social (y política) basada en la oposición minoría-masa. Que sus opiniones políticas van cambiando al compás no sólo de las filosóficas, sino también de los avatares histórico-sociales es indiscutible y los investigadores desde Gaos y Ferrater a Cerezo han asumido la tarea de reseñar las fases o etapas de un pensamiento que se tuvo a sí mismo por "circunstancial». Pero así como desde 1914 hay un oriente en la senda filosófica de Ortega, también lo hay en la política y se llama liberalismo. Es, por tanto, a partir de esta «emoción radical» (más que simple ideario) como hay que interpretar los cambios de Ortega en política, evitando un peligro central: el de substantivar lo adjetivo. Un ejemplo del tipo de enfoque que incurre en tal es el que mantiene que hay un «giro» desde las convicciones liberales en la primera mitad de la década del diez, hacia un "elitismo" ${ }^{4}$ conservador, antidemocrático y protofascista. Más adelante examinaré esta hipótesis. A mi juicio, las fechas clave de la

fiables y esclarecedoras, aunque algunos las encuentren ayunas de matices críticos.)

${ }^{4}$ No deja de ser curioso que la mayoría de los críticos de Ortega reseñen sus análisis basándose en un término que Ortega no empleó nunca: «elite». El Diccionario de la Real Academia de la Lengua no acepta el término "elite" hasta su edición de 1984 y lo hace bajo forma de palabra llana, sin acento esdrújulo, como es usual verlo escrito. 
actividad pública de Ortega son 1914 y 1932; ésta porque es el año en que se retira de la escena política ${ }^{5}$. Y la primera porque en ella adopta la línea teórica con mayores implicaciones para con sus opiniones políticas: la del rechazo del utopismo y progresismo en cualquiera de las esferas de la vida humana, lo que le llevará a distanciarse del componente socialista a que vinculaba, desde sus ideas neokantianas, su posición liberal. Esta nueva visión más matizadamente ilustrada de la cultura y del ideal modernos se ejecuta en Meditaciones del Quijote y consiste en trazar límites y ajustar ritmos en las aspiraciones reformadoras de la razón. El reino del «deber ser» puede terminar por atrofiar la sensibilidad para lo que es. La pretensión de cambio tiene que respetar lo real, contar con su resistencia. En definitiva, Ortega rechaza el «exceso» faústico recordándole al hombre moderno la elemental verdad de que no le ha sido dada la creación ex-nihilo y orienta su crítica contra una sobra de confianza en la capacidad de la razón para dictar el curso de los acontecimientos a lo real. Aunque será inevitable completar el deficit de realidad con el ideal, y por ello, «el sentido del ideal consiste en orientar nuestra voluntad, no en suplantar las realidades» (XI,24).

Esta lucha contra la utopía tiene claras consecuencias para su filosofía política, al menos estas dos: el rechazo de la revolución como instrumento de cambio social; la insistencia en considerar al yo individual como sujeto ético e histórico. La tan controvertida cuestión del «sujeto histórico» está resuelta en Ortega con meridiana claridad: quizá lo aprendiera de su maestro Unamuno: el hombre de carne y hueso. Sobre este suelo firme, basta con girar el enfoque desde la salvación ultraterrena a la estrictamente mundana, adecuada a un período de la historia sin dioses.

5 Véase "Reflexiones sobre Ortega y la política» en donde Rodriguez Huéscar establece, basándose en una declaración del propio Ortega, el fin de cualquier actividad política de éste hacia agosto de 1932. En Semblanza de Ortega, Barcelona, Anthropos, 1994, p. 114. 
Liberalismo es para Ortega posición firme hacia 1914. Su filosofía política, consistente, entre otras cosas, en tener una muy pequeña, con muy pocas evidencias, y éstas, revisables, pues cree que la política es por entero circunstancial y pragmática, puede resumirse en un principio: el liberal, que en rigor, no lo es de una teoría política, sino de su metafísica de la vida humana. Creo que esta convicción no cambia. Ortega preferirá siempre la libertad a cualquier otro bien o valor (aunque en rigor, la libertad no es una cosa ni otra) - bienestar, igualdad, participación, seguridad, etcporque cree que constituye la raíz misma de lo humano. Cuando Europa entre en una época de «olvido» de la libertad volverá a hacer la misma operación intelectual que ya llevó a cabo en 1914. Al precisar lo que entendia por liberalismo aplicó uno de los principios fundamentales de lo que luego será la razón histórica: repristinar el concepto (que es siempre ocasional), ajustarlo al perfil del tiempo, no para que diga otra cosa —eso sería la práctica de la neo-verdad oportunista, descrita por Orwell en 1984 - sino para que rinda su sentido en función de las circunstancias históricas. Así, dice en VNP:

«Cuando se desplazan los problemas materiales y jurídicos de la sociedad, cuando varía la sensibilidad colectiva, quedan obligados los verdaderos liberales a trasmudar sus tiendas, poniendo en ejercicio un fecundo nomadismo doctrinal. Por esta razón es hoy ineludible para el liberalismo hacer almoneda de aquellas ideologías que le han impulsado durante un siglo» (I, 302-303).

Exactamente lo que hace, a raíz de los vuelcos históricos de 1936-39 y 1939-45, en los textos que pasan por ser para numerosos críticos el lamento del liberal arrepentido. Me refiero a «Prólogo para franceses» y "Epílogo para ingleses» añadidos a las respectivas ediciones de La rebelión de las masas y, sobre todo, a Del imperio romano en donde Ortega discute con mayor profundidad el 
problema de la libertad social a la luz de la irrupción de los totalitarismos en la historia.

El autor que mejor antagoniza con las interpretaciones aquí defendidas es Antonio Elorza, quién dedicó un libro ${ }^{6}$ de más de doscientas páginas, merecedor del premio Anagrama de ensayo de 1984, a estudiar la trayectoria política de Ortega (y su sombra). Es posible que en los diez años transcurridos desde su publicación haya caído sobre el libro una fina capa de polvo. Recuérdese que en 1989 aconteció el hundimiento y deshaucio de la utopía marxista-leninista, de modo que ya no quedaron demasiadas dudas acerca de qué tipo de satisfacción había recibido la promesa revolucionaria. Pero no consta a quien esto escribe que los análisis en él vertidos hayan dejado de conformar la visión general que se tiene, en muchos ámbitos, especialmente en los universitarios, del pensamiento político de Ortega. Si sopesamos el desinterés (pues supongo que no es ignorancia) de nuestros pensadores políticos «liberales", afanados en la importación del liberalismo de Popper, Rorty, Darhendorf o en la (necesaria) recuperación de un Tocqueville o un Hayek, es posible que, en efecto, la imagen prevaleciente sea la de un Ortega tibiamente liberal, proclive a sombrías inclinaciones autoritarias.

Una vez que un tópico se aposenta en los corazones de las minorías fácticas que educan a este país no hay forma de erradi-

${ }^{6}$ La razón y la sombra. Una lectura politica de Ortega y Gasset, Barcelona, Anagrama, 1984. Salvo indícación en contrario, todas las citas de Elorza van referidas a este libro. Se dará la página a continuación de la cita. 
carlo, aunque se escriba contra ello? ${ }^{7}$ No obstante, es menester insistir.

Elorza antepone a su investigación unas líneas introductorias, hasta cierto punto transparentes, respecto de las intenciones que le mueven a escribir sobre Ortega y añade otras de balance sobre las conclusiones a las que arriba. Se trataría de buscar un punto de vista crítico, por supuesto, y sistemático, del pensamiento político de Ortega y Gasset, equidistante, 0 , al menos, alternativo al «veneno» de la visión discipular y de su «antídoto», la demonización desde la «izquierda marxista», que impidió que el Ortega político fuera atendido en la misma medida en que lo fueron un Azaña, un Unamuno o un Araquinstain (p. 10). Doscientas cuarenta páginas después se concluye lo siguiente:

«De modo específico, su filosofia politica figura siempre vinculada al objetivo de racionalizar la sociedad civil, la cultura y el Estado españoles, en el sentido de una modernización. Es una tarea que se concibe a sí misma como histórica, incardinada en la práctica social por la mediación del juego articulado de minorías intelectuales rectoras y la masa social, a quien solamente cabe un papel subalterno. La visión elitista, tomada de Nietzsche como medio para diseñar una acción posible

7 Citaré algunos de los mejores trabajos, a mi juicio, que han aparecido últimamente sobre el pensamiento político de Ortega, defendiendo su perspectiva liberal. Además de los reseñados en la nota 3, los de P. Cerezo "Razón vital y liberalismo en Ortega y Gasset", ya citado y su reciente contribución a la Historia de España de D. Ramón Menéndez Pidal, La edad de plata, I, Madrid, Espasa, 1994; especialmente los capítulos V y VI. Javier San Martín, Ensayos sobre Ortega, ya citado, especialmente los capitulos VI y VII. I. Sánchez Cảmara, "El liberalismo de Ortega y Gasset», Madrid, Revista de Occidente, $\mathrm{n}^{2} 108$, mayo 1990 . V. Ouimette, "Liberalismo e democrazia in Ortega y Gasset", en Mondo operario, n 11, 1989. J.M. Herrera, "Los bárbaros y la democracia o sobre las verdaderas fuentes germánicas de Ortega" en Ortega y la fenomenologí, Madrid, Uned, 1992. A. Rodriguez Huéscar, "Reflexiones sobre Ortega y la politica", en Semblanza de Ortega (citado anteriormente). Las contribuciones de Marías, Garagorri y Diez del Corral, entre otros, van en la misma dirección que los trabajos reseñados, pero no pretendo ofrecer una bibliografía exhaustiva. 
frente a la pasividad de la mayoría de la sociedad española, cruzará las etapas del liberalismo social, democracia conservadora y aproximación al autoritarismo, sin mutaciones sensibles» ( $p$. 249. Cursivas añadidas).

Está claro: Ortega pasa por distintas fases de lo mismo: liberalismo, democracia conservadora o autoritarismo son distintas cadencias de una única melodía: "elitismo».

Los puntos de inflexión en la línea del tiempo que describe la evolución política de Ortega son, según Elorza, los siguientes: $1914,1916,1919$ y 1922. El primero de los años citados es el de la conferencia Vieja y nueva política y la creación de la Liga de acción política. Atrás queda una etapa inicial inspirada por el socialismo saint-simoniano, por la práctica sindical de la socialdemocracia alemana y por la visión reformista y pedagógica de los neokantianos de Marburgo. Ahora los acentos se han desplazado hacia la nacionalización de España y la organización de la sociedad al margen de las prácticas políticas usuales, bajo los criterios rectores de la justicia y la eficacia ${ }^{8}$. Ortega, claro está, se equivocaba en su estrategia política:

«El punto débil de la construcción idelógica renovadora apunta a la estrategia política. La pedagogía social encarnada por la Liga trata de conseguir una transformación radical del panorama político, sin utilizar los cauces políticos usuales, trabajando en el orden de la sociedad civil» (p. 79).

Recojo esta observación porque acredita uno de los mecanismos internos de la crítica que Elorza dirige a Ortega en su libro: señalar como una insuficiencia lo que no es tal. Ortega no estaba interesado en el poder político, entre otras cosas, porque sabía que las

${ }^{8}$ La justicia le parece bien a Elorza, pero sobre la eficacia escribe: «El contenido burgués de esta propuesta se aprecia al cifrar en una palabra su significado: la competencia" (p. 74). 
soluciones para España no podían ser administradas ni única ni prioritariamente desde el Estado. El problema de España no es político, diagnostica Ortega, sino histórico; no es la clase política la que está postrada, sino la totalidad del cuerpo social: «la España gobernada estaba tan enferma como ellas [las clases gobernantes]" (I, 274). Es en 1914 cuando Ortega fulmina este juicio. Tampoco tendrá razón Elorza cuando argumente hacia el final del capitulo IV que una señal de la evolución de Ortega hacia posiciones conservadoras es la de la ampliación de su crítica a toda la sociedad española y no sólo a sus clases rectoras (cf. pp 168 y ss.)

Es el mismo término "política» el que induce a confusión porque Ortega limita su significado a la esfera del Estado y de los asuntos del poder público; pero Elorza, sin respetar este uso o discutir expresamente sus limitaciones, impone el suyo, hinchado y omniabarcador: toda cuestión social, humana, es de suyo política. Dicho de otro modo, Ortega tiene una concepción empírica y pragmática de la política, mientras que la de Elorza es "metafísica", de esa metafísica que vuelve a todos los gatos pardos. De ahí que le atribuya pretensiones de las que carece -en el texto citado y en la mayor parte de la obra - al afirmar que buscaba con la Liga «una transformación radical del panorama político" (ibid.).

A pesar de estas puntualizaciones Elorza aprueba aún la intención reformista de Ortega.

Es en 1916 cuando empieza a apartarse del (buen) camino con su adscripción a un perspectivismo de inspiración nietzscheana que trueca por el correcto objetivismo (kantiano) de su etapa anterior. Para que le encajen las cuentas tiene que situar el giro en 1916 y no en 1914, en las palabras preliminares de $\mathrm{MQ}$ «Al lector...", que es donde realmente se produce, pues el reformismo de VNP no casaría con el irracionalismo propio de una concepción perspectivista del conocimiento. La preferencia de Elorza por el texto del El Espectador tiene su razón de ser en que allí se produce, 
por primera vez, la preterición de la política respecto de la filosofía o teoría?.

El bastidor de ideas que convierten a Ortega en un filósofo de la burguesía y en un inspirador (y hasta simpatizante encubierto) del fascismo ${ }^{16}$ es, pues, éste: perspectivismo irracionalista, desprecio de la política y elitismo: «Viraje filosófico, en fin, perfectamente ajustable al retroceso en las esperanzas de impulsar el cambio político y que viene a reforzar, tanto los componentes nietzscheanos encubiertos temporalmente por Kant como el aristocratismo en la visión de las relaciones sociales...» (p. 89). Examinemos brevemente cada elemento, a saber: 1) la influencia de Nietzsche; 2) el desprecio de toda política; 3) el aristocratismo como eje de las relaciones sociales.

\section{Influencia nietzscheana}

El ascendiente de Nietzsche sobre Ortega es para Elorza el único relevante en materia de epistemología. Ni Husserl ni Scheler ni Dilthey por citar sólo tres de los acreditados por estudios solventes, hacen al caso. El aparato crítico en que se apoya, resulta, dada la complejidad del asunto, algo exiguo. De un lado, el trabajo

9 Dice Elorza: «Y por primera vez, con la desilusión apunta el reproche y la vejación dirigidos, no ya contra la 'vieja política', sino contra la actividad política en general, considerada como práctica de naturaleza inferior e incluso negación viva de la búsqueda de la verdad» (p. 87).

10 Elorza se guarda de llamar "fascista» a Ortega, asi, con todas las letras Se conforma con sugetirlo. Hacia 1919 «Ortega es contrarrevolucionario, pero no abre ahora la menor espita al fascismo" (p. 131. Cursiva añadida). Y analizando las ideas de El tema de nuestro tiempo, así como los textos que Ortega publica por estas fechas - primera mitad de los años veinte-, afirma: "Por un momento, el liberalismo resulta eclipsado en nombre de una doctrina de exaltación individual, no muy alejada del naciente fascismo" ( $p$. 140). Es decir, que "proclama la equivociaad del liberalismo y le contrapone el 'sublime ademán deportivo' del heroísmo individualista" (ibid.). De entre los artículos que enumera Elorzà y que examina a continuación, se olvida de incluir "Ideas de los Castillos" (1925). Da la casualidad de que en este artículo, que contiene la más enérgica afirmación del "ademán deportivo", Ortega hace su más elogioso examen del liberalismo (cf., II, 424 y ss). 
de Sobejano Nietzsche en España ${ }^{11}$ y de otro, la conocida obra de Lukacs El asalto a la razón, de la que un sociólogo español dijo con gracia y precisión que era un tratado de teología (staliniana) de escaso valor filosófico ${ }^{12}$.

De la investigación de Sobejano hay que señalar que goza de notable prestigio, por lo que se ha convertido desde su publicación en obligado punto de referencia cuando se discute la presencia de Nietzsche en Ortega. Su amplitud en la comparación de las respectivas obras y la claridad expositiva hacen de ella una investigación imprescindible, pero el propio Sobejano advierte sobre sus límites. Después de decir que no está pensada para estudiosos de filosofía, añade: «No es nuestro intento analizar una filosofía en contràste con otra, en su génesis, en el alcance de sus métodos, principios y consecuencias doctrinales...» (p. 526). Parece razonable esperar que quien vaya a hacer un uso filosófico y sistemático de la investigación de Sobejano, complemente el cotejo de textos y los parelismos establecidos con argumentaciones que justifiquen que las mismas nociones «dicen» lo mismo en uno y otro autor. Pero esto es lo que, normalmente, no se halla entre los críticos que subrayan la importancia de Nietzsche en la génesis de algunos motivos orteguianos. Tal influencia está fuera de duda, como lo está la de Platón, Aristóteles, Leibniz, Kant, Hegel, Simmel, Dilthey, Husserl o Heidegger. Pero si se pretende destacar la de Nietzsche como una específicamente dominante, creo que habrá que demostrarlo. En mi opinión, se trata de un asunto muy complejo, apenas estudiado, a diferencia de otras influencias que han recibido más atención.

Acaso no sea mera casualidad que hayan sido los críticos católicos $^{13}$ antes que Elorza quienes más han destacado la influen-

11 Madrid, Gredos, 1967.

12 Por otro lado, el propio Elorza reconoce que las descalificaciones, basadas en una teoría del conocimiento intuicionista e irracionalista, no alcanzan plenamente a Ortega. Op. cit., p. 90.

${ }^{13}$ En J. Sánchez Villaseñor lo siguiente: «Empero, bajo el nefasto influjo 
cia nietzscheana. Los primeros para reforzar la apariencia anticristiana de Ortega, éste para «explicar» el origen de su aristocratismo, debilitándolo así por asociación con el lugar común, hasta no hace mucho, de un Nietzsche afín al nazismo. Y también coinciden en la superficialidad del tratamiento: se señala un rasgo general y aislado - vida, perspectiva, aristocracia, defensa del individuo frente a la masa - pero no se entra en el significado, muy complejo a veces, que esos conceptos adquieren en sus respectivas sistematizaciones internas. Comentaré algún caso. Quizá Sobejano tenga razón cuando encuentra «alguna injusticia grave respecto a Nietzsche... en ciertos silencios de Ortega..." (p. 535); pero no acierta en su ejemplificación cuando cita el siguiente texto de Prólogo para alemanes, en el que se eludiría el reconocimiento del autor del Zaratustra como precedente de la idea de vida: «hoy sabe todo el mundo que la Idea de la Vida como realidad radical sólo se podía llegar, por influencia extraña, a través de dos pensadores: Dilthey y Kierkegaard" (VIII, 45-46; cit en Sobejano, p. 535). Repárese en que se habla de la idea de vida como realidad radical, por tanto, no de la vida como género, como "cosa» que hay en el mundo, sino de la vida como subjetividad. El hilo conductor es, pues, el de la subjetividad transcendental, tal y como Kant y el idealismo alemán hasta Husserl la plantean. Dilthey es la «salida» hacia la razón narrativa; Kierkegaard, el primer autor que piensa con claridad la vida humana como realidad existenciaria, y por ello los cita Ortega. Otro caso abierto a controversia, especialmente

de Fausto y Zaratustra entona ditirambos a la vidan. Pensamiento y trayectoria de José Ortega y Gasset, ensayo de crítica filósofica. México D.F., 1943, p. 75). En otro lugar acusa a Ortega de plagiar «la doctrina nietzscheana que establece una moral para los señores y otra para los esclavos" (169-170). Del mismo tenor son las observaciones de Roig Gironella en su Filosofía y vida, Barcelona, ed. Barna, 1946. Se trata de edificantes "vidas de santos", pero al revés. Algo más consistente es la crítica de D. Marrero en Ortega, filósofo mondain (Madrid, Rialp, 1963), quien se sirve de un curioso método: cotejar los grandes lugares de Nietzsche, p.e., Más allá del bien y del mal, con los menudos artículos de Ortega, como «Leyendo Le petit Pierre de Anatole France". 
relevante en el libro de Elorza, es el relativo al perspectivismo, que en Nietzsche es un principio gnoseológico, una ley del intelecto humano, mientras que en Ortega lo es de la realidad misma: es la vida humana (no el individuo cognoscente que la habita) lo que es o consiste en perspectiva y tan miembro de ella es el yo-punto de vista, como la cosa. No es el ojo quien crea el escorzo: las cosas tienen, son escorzo. Hay, pues que discutir si, como insiste Rodríguez Huéscar ${ }^{14}$, el perspectivismo orteguiano debe más a Leibniz que a Nietzsche.

$Y$ en lo que respecta al aristocratismo, ¿por qué primar a Nietzsche sobre Platón o Burckhardt? Es evidente que Ortega había leído con atención la República, cuyo Mito de la Caverna es, entre otras cosas, el lugar clásico del aristocratismo intelectual defendido por Ortega. Lo mismo se puede decir, por ejemplo, del Ortega crítico de la democracia: ¿por qué Nietzsche en Ortega y no Tocqueville como fuente común en la que ambos beben? Con estas observaciones, sólo pretendo insinuar que hay mucho que investigar. Algo se ha hecho ya. En el estudio del profesor Cerezo La voluntad de aventura ${ }^{15}$, se trata a fondo la influencia de Nietzsche en Ortega. Acepta el planteamiento de Sobejano, pero lo matiza y complementa ampliamente. De entrada, sitúa ese influjo en juego con los no menos decisivos de Goethe y Fichte para el análisis de la voluntad moral del héroe orteguiano. Sobre este hilo, trenza algunos motivos de raíz nietzscheana: la moral como creación, la contraposición entre el espíritu industrial y el guerrero: la virtud utilitaria, frente a la zaratustriana "virtud que hace regalos», los valores de la "vida ascendente», etc. Pero también reconoce que este Nietzsche está pasado por el cedazo de Aristóteles ${ }^{16}$; o que, a instancias del predominio del motivo del destino sobre el del juego, Fichte le gana finalmente la partida a Nietzsche-Goethe (p.

${ }^{14}$ Perspectiva y verdad, Madrid, Taurus, 1965, n. 158, pp. 429-431.

${ }^{15}$ Barcelona, Ariel, 1984.

${ }^{16}$ Op. cit., pp. 143 y 368 . Lo cernido así puede resultar notablemente distinto de la materia original. 
175). Destaca como el más nietzscheano de los libros de Ortega $E l$ tema de nuestro tiempo, en lo que coincide con Sobejano; (por mi parte añadiría que en el contexto de la totalidad de la obra orteguiana, éste resulta ser el menos "orteguiano» de sus libros). Hay, sin embargo, un aspecto del análisis de Cerezo que encuentro discutible, el relativo a si la "voluntad de poder" nietzscheana encierra una clave para interpretar la "voluntad del héroe» y, posteriormente, el complejo y decisivo concepto de "vocación", punto que me limito a constatar, porque no es susceptible de discusión ahora. A modo de resumen afirma Cerezo que «Nietzsche es una enorme herencia subterránea, de la que el propio Ortega no logra hacerse una idea cabal» (p.352); pero se trata de eso, una herencia, por lo que prefiere los oportunos términos de «inspiración» $y$ «vecindad» (p. 37).

En esta línea de destacar el paralelismo y convivencia entre las dos filosofías se han publicado recientemente dos trabajos que, sin limitarse a la cuestión de las influencias, encuentran sugestivos complementos entre ambas obras. Me refiero a Ortega y Heidegger de Antonio Regalado y Ateísmo difícil de Julio Quesada ${ }^{17}$.

\section{Minusvaloración de lo político}

Además de deberle Ortega a Nietzsche su perspectivismo, también es la influencia a considerar ante el cambio de valoración de la política, teorizado en «Verdad y perspectiva» (1916) y en "Democracia morbosa» (1917). En el primero de estos artículos, se dice que la verdad (descubrimiento y contemplación de lo que las cosas son) es incompatible con la política; en el segundo, que la actitud democrática, fuera del ámbito de la política, es decir, como principio inspirador en las esferas de la cultura (arte, religión,

${ }^{17}$ Madrid, Alianza, 1991 y Barcelona, Anagrama, 1994, respectivamente. Véase de éste último la III parte, "Sólo nos es segura la inseguridad" y del primero el final del cap. I "Voluntad de poder y razón vital» y el cap. II "De la voluntad de poder como arte al ser ejecutivo". 
moral o ciencia), constituye la raíz de una grave enfermedad, cuyo fondo es el resentimiento diagnosticado por Nietzsche.

La política es, para Ortega, ya se ha dicho, una actividad superficial: gestión de medios en el ámbito de las transformaciones materialmente posibles, sistematización de utilidades, toma de decisiones funcionales, aportación de recursos, etc. Los fines y las disposiciones de los individuos para desear estos, así como la delicada cuestión de qué es posible y qué imposible en un momento histórico dado pertenecen al ámbito de la cultura y condicionan la política. La ausencia en el análisis de Elorza de este decisivo concepto para entender la trayectoria intelectual de Ortega (en la cual hay que enmarcar la política, si es que se quiere entender algo) explica algunas de sus imputaciones críticas: si se aleja de la política es porque se siente despechado por ella; ¡bendito fracaso que determinó que se dedicara a escribir filosofia!

Ortega consideró antes de 1914 que el problema de España era un problema de cultura en un doble sentido: a) como carencia material de ésta, en comparación con el nivel de las naciones europeas; y b) como atrofia de determinados principios y normas de acción (virtudes civiles, respeto por el trabajo bien hecho, etc.) e hipertrofia de sus opuestos. La incansable labor en periódicos, conferencias, libros y cátedra revela el esfuerzo y el éxito (parcial) alcanzado por Ortega en los quince años siguientes frente a la primera carencia. La segunda era más difícil de vencer porque la crisis profunda de la modernidad ilustrada (de la que Ortega se sentía heredero, lo que no le impedía ser crítico con ella) dificultaba la transformación de la cultura en principios de vida. Educación, "pedagogia social» fueron los remedios a los que recurrió Ortega en su intento de contribuir a salvar la parte de su circunstancia que le era España. Probablemente no bastaron (aunque es esto algo a determinar teniendo en cuenta las complejas cuestiones de los ritmos históricos).

Que no ignoraba la extrema complejidad de las relaciones entre cultura y política lo demuestra el que reflexione una y otra vez sobre la función social del intelectual y la muy delicada cuestión 
de la que es inseparable: las relaciones entre la contemplación y la acción. El contexto en que hay que situar su defensa de una acción de las minorias sobre las masas es éste de la «acción» cultural que se centra en su objeto: producción científica o artística de la que, como un efecto no buscado, brotará ejemplaridad; nunca, por tanto en el inmediato de la acción política. Ortega lo deja más que claro al insistir en que el morbo nacional, asumido luego por la época en que entraba Europa, era el de la "acción directa», es decir, la evitación de rodeos, de mediaciones. Por ejemplo, la mediacion del parlamentarismo en la vida pública. La ejemplaridad que Ortega reclama como eje de una relación eficaz entre la minoría y la masa está basada en la larga, costosa y paciente «obra bien hecha». Es minoría cualquiera capaz de sacrificar la inmediatez de la reclamación de soluciones dirigida hacia afuera al «trabajo en lo negativo» (para decirlo con una expresión vagamente hegeliana) que tiene que salir de uno mismo.

\section{3. ¿Aristocratismo en política?}

Con esto hemos llegado al tercer elemento de la crítica de Elorza. $\mathrm{Y}$ también encontramos a Nietzsche en el origen del «elitismo» orteguiano. En 1923 con El tema de nuestro tiempo (TNT) profundiza Ortega en el motivo del aristocratismo, presentado ya en escritos anteriores. El libro es importante porque encierra la clave para interpretar «el repliegue ideológico de Ortega a comienzos de los años veinte» (p. 137), al tiempo que le permite expresar a través de su concepto de generación, nada más y nada menos que «la intensidad del fracaso sentido en los años inmediatamente anteriores» respecto de su intervención en política (ibid.). Es la segunda vez que Elorza recurre al delicado expediente crítico de sostener que las ideas filosóficas orteguianas son el reflejo de un fracaso personal, por lo que pienso que debe estar convencido de su eficacia y oportunidad, así como de la imagen de Ortega con la que es congruente. Sería, pues, Don José un señor catedrático 
entretenido en sus papeles y conferencias, pero obsesionado exclusivamente con la política.

Lo que Elorza no nos llega a decir es si mueve a Ortega una baja pasión o una elevada disposición de alma; de interpretar por mi cuenta, me inclino por la primera disyuntiva habida cuenta de que era un burgués incapaz de comprender la verdadera naturaleza de los acontecimientos históricos, asustadizo ante el vibrante espectáculo de las huelgas revolucionarias. No hay exageración en mis palabras. Vea el lector su interpretación de la visita de Ortega a Córdoba, en donde le sorprende una huelga de jornaleros: «El filósofo viene aterrado de la vieja ciudad» (p. 125). Y por si fuera poco, se eleva este episodio a la categoría de «caída de Damasco» respecto de la posición de Ortega ante el problema social (p. 126). La tesis central de Elorza viene a ser que ante el giro hacia el bolchevismo del movimiento obrero, Ortega acentuaría sus críticas por considerar que «la dictadura del proletariado» es «incompatible con el principio básico de la libertad individual" (ibid.). ¿Claro! Lo que no lo es tanto es que ésta sea la causa de que Ortega se incline, pocos años después, hacia soluciones políticas dictatoriales.

Así, todo lo que escribió sea sobre el vuelo de las aves anilladas, la razón histórica, la reforma de la universidad, el futuro de Europa, o el problema del mal en Leibniz debe ser interpretado en clave "ideológica»: puesto bajo la luz del sofión político que Ortega acabe de recibir, se revelará inevitablemente su "oculto" significado. La cosa llega a ser más grave y, a veces, Elorza. parece sugerir que hay en Ortega falta de veracidad, es decir, voluntad de manipular la verdad como un vulgar plumífero que cobrara por ello o que aspirara a resarcirse del fracaso de sus inmoderados y siempre insatisfechos afanes políticos. Sé que el lector puede considerar excesiva, dada su gravedad, la imputación que hago a Elorza. Si es así, le ruego que lea con atención lo siguiente: "Ortega no está dispuesto a aceptar que las normas objetivas que han de regir el funcionamiento del universo social y político puedan trazarse desde la razón pura» (p. 142). No se dice que 
Ortega no cree o que concluye, siguiendo argumentaciones erradas, tal o cual cosa contra Kant, sino que no le da la gana ("no está dispuesto") de aceptar una verdad (que Elorza le atribuye conocer) que no le conviene por motivos políticos. $Y$ en efecto, pocas líneas después leemos: «El viraje copernicano que a su vez intenta acometer en el sentido del raciovitalismo, tiene, pues, sus raices, no en desacuerdos teóricos de naturaleza filosófica, sino en el rechazo radical de las implicaciones revolucionarias del pensamiento kantiano, en estrecho enlace con el presente» (Ibid. Cursiva añadida).

Sin duda, Elorza aplica con animado fervor las categorías del materialismo histórico a la obra de Ortega, lo que revela ipso-facto el subjetivismo burgués de éste. Evidentemente, no ha sido el único en servirse de dicho procedimiento. Entre los historiadores, Tuñón de Lara, en su reputado Medio siglo de cultura española (18851936), ya citado, concluye que la teoría de Ortega «frena la acción de los hombres a transformar la realidad social» (pp 230-231). Confrontada la doctrina orteguiana con la Máxima Verdad, no resulta aprobada. En consecuencia habrá de ser «ideología", según la definición que del término se nos da en los preliminares (p. 13). Recuerdo al lector que según la definición al uso, lo que no es «ideológico» es «científico». $Y$ así, Tuñón no tiene pudor en reconocer que en los escritos de don Antonio Machado hay ideas "que preceden a lo que luego es ciencia» (p. 15). Más interés tiene la observación sobre la inexistencia de una burguesía liberal, a quien Ortega dirigiría sus mensajes de formación de minorías cultas, orientadas hacia la reforma del pais postrado por la política de la Restauración (p. 200). Siendo esto cierto, el historiador, sin embargo se olvida de un hecho bien acreditado en múltiples escritos de Ortega: que éste, consciente de tales ausencias se dirigió una y otra vez a las formaciones obreras y en especial al Partido Socialista de Pablo Iglesias para que asumieran esa función histórica de salvar a la nación. Que prefirieran el radicalismo 
revolucionario es algo que también explica el fracaso del proyecto político orteguiano ${ }^{18}$.

Pero vayamos al detalle de la crítica de Elorza a la teoría de las minorías. Su presentación «oficial» tiene lugar en la segunda parte de España invertebrada (EI), que lleva por título «La ausencia de los mejores», aunque es en TNT donde se da justificación filosófica a la noción de "minoría», al engarzarla en el concepto de "generación»:

"Cada generación, -escribe Elorza- como todo grupo humano, cuenta con una 'anatomía jerarquizada', cuya expresión ahora va más allá del tradicional juego minorias/masas, para reflejarse en la interacción observable entre individualidades egregias y masas de hombres vulgares. Dos niveles articulados por unas necesarias relaciones de dominación de los primeros por los segundos" (p. 138).

18 Hay más ejemplos de crítica marxista a Ortega. En otro libro, muy influyente en los años setenta y ochenta, La edad de plata (1902-1939) de J. C. Mainer se dice lo siguiente: "Por otra parte, media una evidente distancia entre el Ortega que hacia 1910 proclama la socialdemocracia como nueva frontera del liberalismo y el que en 1920 busca en las páginas de España invertebrada una fórmula estatal que remedie la pavorosa crisis del capitalismo español que sobrecoge a nuestras finanzas, una vez cerrado el ciclo expansionista auspiciado por la guerra europea» (Madrid, Cátedra, 1981, p. 143). Y por si el lector no ha terminado de entender lo que se oculta detras de los líbros, encima bien escritos, de este temible emboscado, se irisiste en que estos tienen «la rara virtud de ofrecer en su dimensión más pura los principios de la racionalidad burguesan. Naturalmente, no se nos explica qué otra racionalidad no burguesa hay. Wittgenstein y Husserl no son en cambio burgueses a juzgar por el lamento del señor Mainer, que echa de menos sus interesantes teorías epistemológicas en Ortega, prueba más que suficiente para concluir que Mainer o no ha leído o no ha entendido a Ortega, pues desde 1914 es su filosofía una intensa reflexión sobre esas cuestiones. Y en una perspectiva más (aparentemente) filosófica, del que no merece la pena entresacar una cita, pues todo el libro de F. Áriel del Val sería citable a efectos de mostrar la tendenciosidad y confusión en el tratamiento de Ortega, Historia e ilegitimidad. La guiebra del estado liberal en Ortega. Fragmentos de sociologia del poder. Madrid, U. Complutense, 1984. 
A continuación cita a Ortega:

«La vida de la individualidad egregia consiste precisamente en una actuación omnímoda sobre la masa. No cabe, pues, separar los 'héroes' de las masas. Se trata de una dualidad esencial al proceso históricon (III, 147).

Resulta discutible que haya diferencia conceptual entre los términos "minoría» e "individualidad egregia». Si es así, Elorza debería señalar qué añaden las nuevas expresiones. Por otro lado, no es posible hallar en la descripción orteguiana -ni aquí ni en otros lugares ni en lenguaje directo ni en metáfora- una idea que equivalga a la interpretación que da Elorza de las relaciones entre minoría y masa como articuladas "por unas necesarias relaciones de dominación». La cita de Ortega recogida por Elorza (y copiada supra) no sólo no contiene tal idea, sino que ha sido tomada justo después de ciertas afirmaciones que son incompatibles con dicha lectura. Así, justo antes de donde comienza la cita «La vida de la individualidad egregia...», leemos:

"Las masas humanas son receptivas; se limitan a oponer su favor o su resistencia a los hombres de vida personal e iniciadora. Mas, por otra parte, el individuo señero es una abstracción. Vida histórica es convivencia» (III, 147. Cursiva añadida).

Ante la insistencia orteguiana en que las minorías no son los grupos privilegiados (de sangre, dinero o poder social) históricamente dados (por ejemplo, en El, III, 95), recurre al curioso expediente crítico ya conocido: Ortega enmascara:

"Ortega se cuida en este punto de enmascarar sus propios puntos de observación, advirtiendo que en la categoría negativa de 'masa' no sólo ha de encuadrarse la masa proletaria, sino también 'las masas con mayor poderio', las de las clases superiores» (p. 157). 
Elorza ignora aquí las críticas de Ortega contra el «lock-out» que la patronal catalana decidió en $1919^{19}$ o los juicios vertidos contra las clases dirigentes del país. El fondo del asunto es el revolucionarismo de la clase obrera, frente al cual Ortega estaría defendiendo nada menos que "un modelo contractual» e insistiendo en que todas las clases sociales intentan «alcanzar sus objetivos por medio del acuerdo; la acción directa, el rechazo de la mediación por parte de la clase obrera, es pues el enemigo principal» (p. 157) ${ }^{20}$. Volviendo al núcleo de la crítica, Ortega enmascara. ¿Quiere decirse con tan ambiguo término que Ortega miente al lector o que se miente a sí mismo? No lo aclara Elorza ${ }^{21}$, pero hay que reconocer que Ortega enmascara mucho porque una y otra vez repite que no se trata de minorias de dominio, sino de ejemplaridad, que no se refiere a grupos organizados socialmente, dotados de instrumentos

19 "En tiempo de lock-out" $(X, 597-600)$. He encontrado esta referencia en el artículo de Evelyne Lopez-Campillo sobre "Ortega y la sociedad civil española" (Cuadernos hispanoamericanos, Madrid, 1984, n 403-405, pp. 529537). La hipótesis de un Ortega defensor de los intereses de una clase de la sociedad española de su tiempo, no halla confirmación en este trabajo que muestra a las claras la pluralidad de direcciones de las críticas orteguianas a todo aquello que no le gustaba en la sociedad civil española.

20 Elorza deberia haber explicado en 1984 cómo es que la clase obrera y los políticos de izquierdas se habian vuelto orteguianos pocos años antes. (Aludo, claro está, a los "Pactos de la Moncloa»).

21 Más adelante, vuelve sobre el asunto del enmascaramiento y afirma que lo contrasta empíricamente. Para ello se sirve del expediente de invertir las tesis de un artículo - «Imperativo de intelectualidad» (XI, 11 y ss)-en que Ortega repite sus ideas ya expuestas en otros lugares, insistiendo en que el intelectual no debe intervenir directamente en política. Es lo que venia diciendo y haciendo desde 1914 y antes: actuar según el modelo de su pedagogia social, analizando los sucesos políticos del dia a dia, pero sin pertenecer a grupos politicos o ejercer presión fuera del cauce de sus palabras publicadas. Nada cambia con este artículo que, según Elorza, marca un punto de no retorno en las relaciones (de divorcio) entre pensamiento y política. La inversión de las tesis del artículo dan por resultado, pues, la exposición inversa, pero yo no advierto que Elorza demuestre

nada. Se limita a realizar otro juicio de intenciones diciendo lo que Ortega quiere decir -y no dice: "no hay que intervenir porque mi intervención ha fracasado, es el razonamiento latente y consciente encubierto de esta versión actualizada del viejo apólogo de la zorra y las uvas" (p. 167). 
de poder - financieros, políticos, industriales o militares - sino que es el esfuerzo creador personal lo que sitúa al individuo en disposición de ser minoría, lo que será socialmente relevante si y sólo si la masa lo reconoce. Es este un aspecto de la teoría orteguiana especialmente desatendido por sus expositores "progresistas»": la masa necesita de la minoría, pero también la minoría de la masa. De hecho, la insubordinación de las masas ha sido precedida históricamente por la deserción de las minorías. Aunque es preciso reconocer que el análisis orteguiano es vacilante en algunas ocasiones, responsabiliza a las minorías tanto o más que a las propias masas. El rasgo más característico de la historia española es:

«la desproporción casi incesante entre el valor de nuestro vulgo y el de nuestras minorias selectas. La personalidad autónoma, que adopta ante la vida una actitud individual y consciente, ha sido rarísima en nuestro país. Aquí lo ha hecho todo el 'pueblo', y lo que el 'pueblo' no ha podido hacer se ha quedado sin hacer» (III, 109).

Solo que hacia 1930 la situación se agrava porque el autismo de las masas se generaliza. La hipótesis de normalización histórica que Ortega propone, la salida de la crisis (española y europea) sólo puede venir dada por: $1^{2}$ ) la emergencia de una minoria que aporte soluciones a los problemas del momento; $2^{9}$ ) el reconoci-

22 Dos recientes publicaciones - de muy desigual tamaño y calidadconfirman la actualidad de este enfoque. La biografia de Ortega recientemente vertida al castellano José Ortega y Gasset. El imperativo de la modernidad (Madrid, Espasa, 1994) de R. Gray, aunque matiza bien muchos de sus análisis, termina por "condenar" a Ortega al limbo de los filósofos "conservadores" y por considerar relevante la crítica marxista de Tuñón de Lara. El artículo de E. Subirats "Cuarteto español" contiene lindezas como la siguiente: "Y se trata además de un concepto de élite que nunca pudo trazar precisamente con nitidez una distancia con respecto a su versión nacionalsocialista, tal como se implantó en España tras la derrota republicana». Letra internacional, $\mathrm{n}^{2} 28$, mayo 1993 p. 23. 
miento de la ejemplaridad de las soluciones y actitudes de las minorías, y de su secuela, la docilidad. Ahora bien, esta docilidad nada tiene que ver con el dominio del poderoso, sino con los mecanismos que hacen posible la convivencia social. Puede explicarse lo que Ortega entiende por «docilidad» si observamos que en el proceso de creación de la opinión pública, hay necesariamente dos tipos de aportaciones: quienes crean las opiniones y quienes las sostienen y propagan. Ortega pensaba que no era posible dirigir una nación sin tener detrás a la opinión pública, última fuente de legitimidad política, pero era igualmente necesario que hubiera tal institución, es decir, que la sociedad no estuviera atomizada por la anomia, el aislamiento y el particularismo. Las minorías tienen esta función histórica. Cuando Ortega escribió La rebelión de las masas estaba en condiciones de observar que en España había ya ciertas minorías. No era distinto el caso en Alemania o Austria, en donde el nivel de las minorías cultas era de una brillantez sorprendente, aunque, como en España, sin ninguna eficacia socializadora. De ahí que en los años treinta, el fenómeno europeo a destacar fuera, específicamente, el de la rebelión de unos hombres que no estaban dispuestos a reconocer ninguna excelencia ni a aprender de ella disciplina, paciencia 0 sentido del deber.

Por otro lado, hay que insistir en que la docilidad pertenece a planos de la vida humana estrictamente prepolíticos y es común a todo hombre socializado, pues la condición de «egre-gio» lo será en un único respecto: normalmente el de su vocación profẹsional, mientras que en multitud de otros será «masa». Es más, puede servir de criterio de distinción entre minoría y masa la capacidad de un individuo para reconocerse masa, aceptar, por tanto, el imperativo de docilidad, imperativo moral en última instancia, pues en él reside la única posibilidad de mejorar la propia conducta $y$, en consecuencia, de contribuir a la justicia y a la felicidad de la comunidad en la que ha de resolver su vida individual. En este sentido es en el que hay que interpretar la observación de Marías respecto de que la distinción minoria-masa 
es, sociológicamente hablando, una distincion funcional y no substancial, de identidad o propiedad de determinados individuos $^{23}$.

Cuando se contrae la distinción minoría-masa al plano de la política resulta ser una simpleza cómodamente rebatible. Y si encima "política» es un substantivo cargado con todo el pathos de la moral y la religión -es decir, un falso mito- es fácil explicar que la doctrina orteguiana haya despertado tanta descalificación. Porque resultaría entonces que Ortega no estaría sólo atacando la vulgata marxista y su teoría histórica (Elorza tiene toda la razón en señalar una y otra vez que Ortega defiende una visión de la política profundamente antirrevolucionaria), sino que rechazaría igualmente los grandes principios ético-políticos de la modernidad: la libertad individual, la justicia social y la igualdad de oportunidades, entre otros. Sin embargo, el liberalismo (democrático y reformista) es intimamente consistente con la teoría de las minorias y con la caracterización de la política como una actividad culturalmente secundaria de la vida humana. Una discusión en profundidad de la teoría de las minorías selectas no puede llevarse a cabo espigando aquí y allá en los artículos que Ortega escribió para los periódicos urgido, las más de las veces, por el suceso del dia. Es preciso también encajarlos en su visión metafísica de la vida humana como realidad radical que abarca una antropología, una epistemología, una teoría social y una teoría de la historia. Nada de esto se halla en Elorza ni en otros críticos que han compartido con él la descalificación de sus intervenciones en la vida pública española durante la primera mitad del siglo XX.

El círculo de la evolución política de Ortega se cierra, explica Elorza, hacia 1924. Nada quedaría del liberalismo de VNP en un espectador proclive «a la conveniencia de una dictadura transitoria» (p. 168) ¿Pero es correcta esta interpretación? ¿La refrenda lo escrito por Ortega? ¿Abandona su liberalismo? Recordemos que

23 Véase La estructura social, Madrid, Revista de Occidente, 1972, pp. 63 y ss.; y Ortega. "'Las trayectorias, Madrid, Alianza, 1983, p. 251. 
abría VNP reflexionando sobre la tarea del auténtico político, consistente en declarar lo que es, actividad intelectual que viene a ser opuesta a la del utopista: el que declara «lo que debe ser». El primero se equivoca o acierta porque ancla su interpretación en lo real. El segundo se mueve en medio de sus desiderata y cree que los demás hacen lo mismo. Cuando Ortega en las citas que recoge Elorza de "Ideas políticas» (XI, 23 y XI, 35) para demostrar el "giro conservador", describe la posibilidad de que advengan dictaduras sobre Europa y el efecto purificador que esto tendrá sobre el liberalismo - que sigue Ortega considerando el suelo efectivo del momento histórico- está prediciendo hechos que luego han ocurrido. Dictaduras militares y totalitarias han asolado la faz europea hasta desembocar, en 1989, en la descomposición de la más pertinaz de todas ellas. Entre 1924 y 1989 transcurren sesenta y cinco años. Ortega prevé, pues, un ciclo histórico que se ha cumplido con toda precisión. Quien lea aquellas Ideas políticas, publicadas en El Sol hacia 1924 reconocerá en su autor al impertérrito liberal que sabe que todavía «ciertas libertades no son (...) cuestiones políticas sobre las que quepa, en principio, discusión" (XI, 35). 